\title{
Organization and Reactivity of Nanoparticles at Molecular Interfaces. Part I. Photoelectrochemical Responses Involving $\mathrm{TiO}_{2}$ Nanoparticles Assembled at Polarizable Water|1,2-Dichloroethane Junctions
}

\author{
Henrik Jensen, ${ }^{\dagger}$ David J. Fermín, ${ }^{*}, \dagger$ Jacques E. Moser, ${ }^{\dagger}$ and Hubert H. Girault ${ }^{\dagger}$ \\ Laboratoire d'Electrochimie Physique et Analytique and Laboratoire de Photonique et Interface, Institut de \\ Chimie Moléculaire et Biologique, Ecole Polytechnique Fédérale de Lausanne, Lausanne CH-1015, Switzerland
}

Received: May 16, 2002; In Final Form: August 9, 2002

\begin{abstract}
The photoelectrochemical properties of $\mathrm{TiO}_{2}$ anatase nanoparticles were studied at the water|1,2-dichloroethane (DCE) interface under potentiostatic control. The interfacial concentration of the electrostatically stabilized particles can be effectively tuned by the Galvani potential difference and the $\mathrm{pH}$ of the aqueous phase. At $\mathrm{pH}$ values lower than that corresponding to the point of zero zeta potential, the particles assemble at the liquid|liquid boundary region upon positive polarization with respect to the Galvani potential in the organic phase. Upon band-gap illumination, photocurrent responses are observed in the presence of ferrocene in the organic phase. The potential and wavelength dependencies of the photocurrent unambiguously reveal that the photoresponses arises from the transfer of valence-band holes to the redox couple in DCE. The hole transfer is mediated via the generation of $\mathrm{OH}_{\mathrm{s}}{ }^{\bullet}$ at the particle surface. On the other hand, photocurrents of the opposite sign were observed in the presence of TCNQ at pH's higher than 10. In this $\mathrm{pH}$ range, the particles are negatively charged, and the formation of the interfacial assembly takes place upon negative polarization with respect to the organic phase. The effect of the $\mathrm{pH}$ and the Galvani potential difference on the photocurrent suggests that heterogeneous charge transfer is in effective competition with recombination via $\mathrm{OH}_{\mathrm{s}}{ }^{\bullet}$ as well as oxygen evolution at the particle surface. These studies open new possibilities for contactless photoelectrochemical and spectroscopic characterization of nanoparticles in solution in the presence of an electric field.
\end{abstract}

\section{Introduction}

The photochemical properties of $\mathrm{TiO}_{2}$ nanoparticles have been extensively studied in homogeneous phases for a variety of processes including water splitting and the photocatalytic destruction of pollutants. ${ }^{1,2}$ In aqueous media, photogenerated holes are readily captured by $\mathrm{OH}^{-}$, leading to the formation of $\mathrm{OH}_{\mathrm{s}}{ }^{\bullet}$ radicals at the particle surface. This radical can eventually induce the oxidation of species in solution or the formation of surface-bound $\mathrm{H}_{2} \mathrm{O}_{2}$. On the contrary, electrons react more slowly with either oxygen or adsorbed protons. The difference in reactivity of electrons and holes determines the quantum yield of a photochemical reaction, which is also affected by recombination processes. Despite the overwhelming literature on the photochemistry of $\mathrm{TiO}_{2}$ colloids, little is yet known about the properties of these particles as "photoelectrodes" at molecular interfaces.

Mesoporous films based on $\mathrm{TiO}_{2}$ nanoparticles have also been studied as photoactive materials. ${ }^{3-6}$ The behavior of these films as photoelectrodes is affected by the applied bias potential. In contrast to bulk semiconductors, nanocrystalline domains cannot withstand a depletion layer under reversed bias; consequently, electron transport to the back contact occurs primarily by diffusion. $^{7-9}$ The transport properties of electrons are strongly determined by the occupancy of trap states distributed across the film. The trap occupancy is a complex function of the bias

\footnotetext{
* Corresponding author: Dr. David J. Fermín. Tel.: +41 216933162 Fax: +41 21 6933667. E-mail: david.fermin@epfl.ch.

Laboratoire d'Electrochimie Physique et Analytique.

$\leftarrow$ Laboratoire de Photonique et Interface.
}

potential and the illumination intensity. ${ }^{6,9-16}$ Charge transport through the mesoporous metal oxides is an essential aspect in the performance of dye-sensitized nanocrystalline solar cells (DSNSCs), in which electron injection take place from an adsorbed ruthenium dye into the $\mathrm{TiO}_{2}$ film. This charge injection occurs on the subpicosecond time scale, ${ }^{17-20}$ whereas electron transport through the film takes place on a time scale that could be as long as seconds. ${ }^{21}$

Vanmaekelbergh and co-workers have introduced a rather elegant method for studying the photoreactivity of Q-CdSe nanoparticles at interfaces. ${ }^{22,23}$ In this case, a well-ordered array of particles is formed by self-assembly on gold electrodes using rigid spacers. Photoexcitation of the particles leads to electron tunneling across the self-assembled monolayer to the metal electrode. The dynamics of charge transfer was found to be dependent on the length of the spacer. Works by Riley et al. ${ }^{24,25}$ and Vanmaekelbergh et al. ${ }^{26,27}$ have shown that the electronic properties of $\mathrm{CdS}$ and $\mathrm{PbS}$ nanoparticles adsorbed on metal electrodes can be monitored by dynamic photocurrent measurements. In these studies, the kinetics of electron exchange between the metal electrode and the quantum dots is determined by the relative position of the Fermi level of the metal with respect to the band edges of the particles. This energy difference can be controlled by the applied bias potential.

In the present paper, a completely new method is introduced in which the photoelectrochemical behavior of the nanoparticles can be studied without their being confined to an electrode surface. This approach is based on the transfer of photogenerated charge carriers to redox species separated by a polarizable 


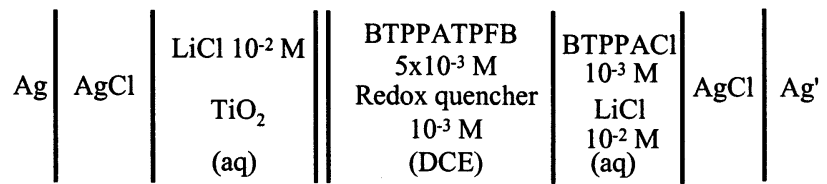

Figure 1. Schematic representation of the electrochemical cell.

interface between two immiscible electrolyte solutions (ITIES). In a series of papers, photocurrent responses originating from the heterogeneous quenching of water-soluble dyes by hydrophobic redox species across the water|1,2-dichloroethane (DCE) junction have been studied in detail. ${ }^{28-33}$ The Galvani potential difference plays a fundamental role in these phenomena, as it affects the driving force for the charge transfer, ${ }^{34}$ as well as the surface excess of the dye. ${ }^{29,30,32}$ The results shown here clearly indicate that the assembly of electrostatically stabilized $\mathrm{TiO}_{2}$ particles is also determined by the Galvani potential difference, as well as by the $\mathrm{pH}$ of the aqueous phase. Finally, it is demonstrated that the transfer of photogenerated carriers across the liquid|liquid boundary manifests itself as photocurrent responses under potentiostatic conditions.

\section{Experimental Section}

All reagents employed were of analytical grade. $\mathrm{TiO}_{2}$ nanoparticles were prepared by the hydrolysis of $\mathrm{TiCl}_{4}$ at low temperature $\left(0^{\circ} \mathrm{C}\right)$ followed by dialysis as reported by Moser and Grätzel. ${ }^{35,36}$ From this method, spherical particles are obtained with a size distribution centered at $56 \AA$. The particles consist of anatase and amorphous $\mathrm{TiO}_{2}$. Electrophoretic measurements provided a point of zero $\zeta$ potential of 4.7. ${ }^{36}$ At $\mathrm{pH}$ 's lower than 4 and higher than 9 , the $\mathrm{TiO}_{2}$ particles are electrostatically stabilized, and no aggregation is observed within several days. ${ }^{37}$ Further details on the properties of the $\mathrm{TiO}_{2}$ sols have been reported elsewhere. ${ }^{36}$

The supporting electrolytes in the aqueous and organic phases were $\mathrm{LiCl}$ and bis(triphenylphosphoranylidene) ammonium tetrakis(pentafluorophenyl)borate (BTPPATPFB), respectively. Details on the preparation of BTPPATPFB have previously been reported. ${ }^{30}$ The composition of the electrochemical cell is schematically shown in Figure 1. The $\mathrm{pH}$ of the aqueous phase was adjusted to 3.5 and 11 by addition of solutions of $\mathrm{HCl}$ and $\mathrm{NaOH}$. An all-glass electrochemical cell with a geometrical surface area of $1.53 \mathrm{~cm}^{2}$ was employed for studies of the $\mathrm{TiO}_{2}$ concentration dependence of the electrochemical responses. This cell features two separate compartments and luggin capillaries for each of the reference electrodes. ${ }^{38}$ The dependence of the photocurrent on the light intensity was studied in total internal reflection from the organic phase to minimize the absorption of UV light in the bulk phases. The design of the $0.22-\mathrm{cm}^{2}$ cell featuring a piston buret has been described in a previous publication. ${ }^{39}$

The electrochemical experiments were performed using a homemade four-electrode potentiostat connected to a PPR1 waveform generator (HI-TEK Instruments). The interfacial capacitance was calculated from admittance measurements using a Stanford Research System SR830 lock-in amplifier. The Galvani potential difference was estimated from the formal transfer potential of tetramethylammonium $\left(\Delta_{\mathrm{o}}^{\mathrm{w}} \phi^{\circ}=\right.$ $0.160 \mathrm{~V})$.

Photocurrent transients were measured using polychromatic light from an Oriel Arc-Xe lamp. A grating monochromator was employed for the photocurrent spectra. The spectral resolution in this setup was typically $5-10 \mathrm{~nm}$. The light intensity was normalized by a high-voltage photomultiplier tube.
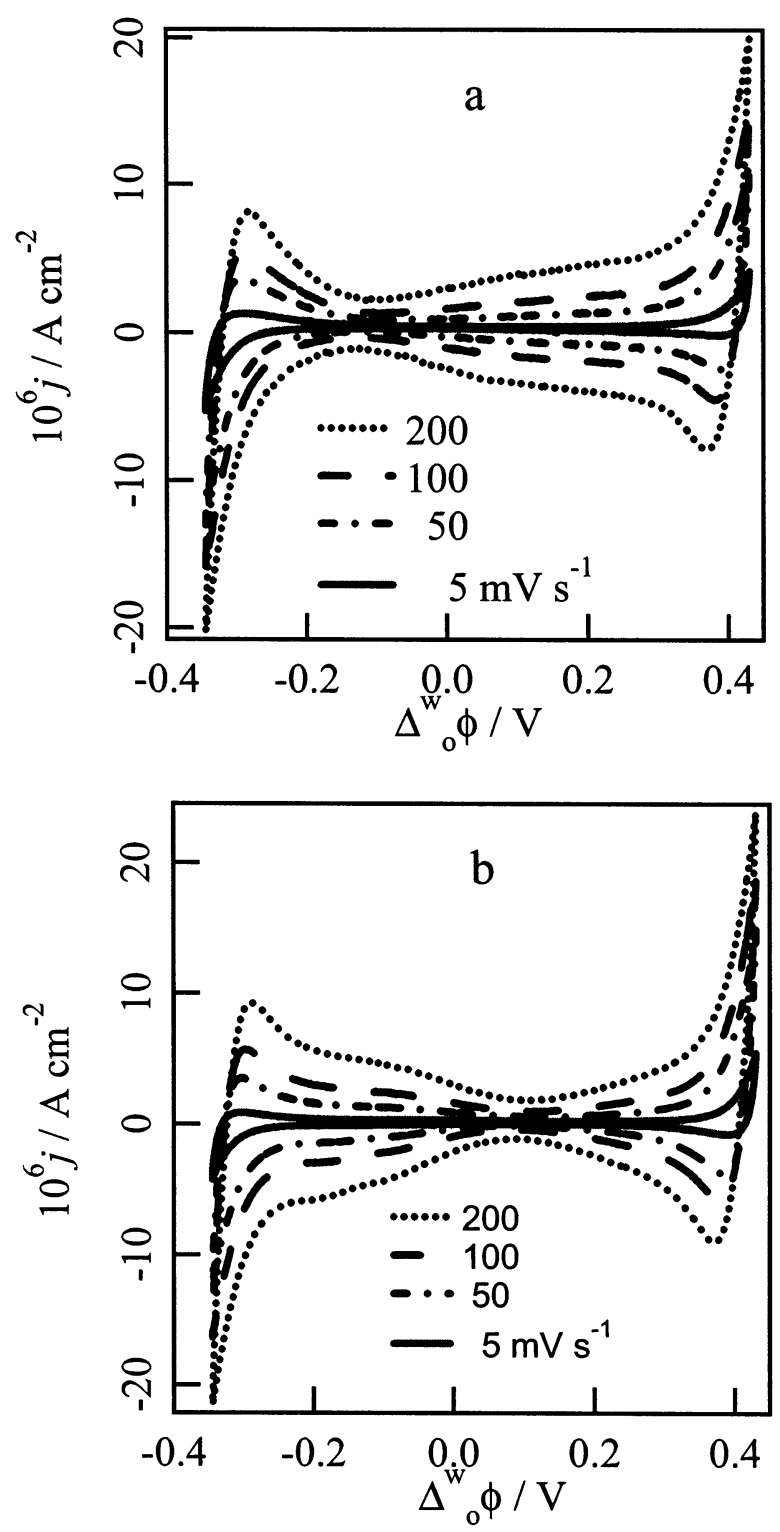

Figure 2. Cyclic voltammograms at various scan rate for a concentration of $100 \mathrm{mg} \mathrm{dm}^{-3}$ of $\mathrm{TiO}_{2}$ at $\mathrm{pH}$ (a) 3.5 and (b) 11 .

Monochromatic photocurrent-potential curves were measured with the 325-nm line from a $\mathrm{CW} \mathrm{He}-\mathrm{Cd}$ laser (Omnichrome Series 74) under total internal reflection (TIR). Quantitative determination of the incident photon flux was complicated by absorption and reflection losses from the glass cell. By measuring the ratio between incident and reflected intensities in TIR, it was estimated that between 40 and $50 \%$ of the illumination at $325 \mathrm{~nm}$ was attenuated by the cell.

\section{Results and Discussion}

3.1. Electrochemically Induced Assembly of $\mathrm{TiO}_{2}$ at the Water|DCE Interface. The effect of $\mathrm{TiO}_{2}$ particles on the voltammetric behavior of the water|DCE junction at $\mathrm{pH} 3.5$ is exemplified in Figure 2a. The transfers of $\mathrm{Li}^{+}$and $\mathrm{Cl}^{-}$from the aqueous phase to the DCE phase establish the positive and negative limits of the potential window, respectively. No faradaic signal is observed within the polarizable window, indicating that the $\mathrm{TiO}_{2}$ particles remain in the aqueous phase in this potential range. However, it can be observed that the capacitive current increases at positive Galvani potential differences for an aqueous electrolyte with a $\mathrm{pH}$ of 3.5. This behavior is 
consistent with the fact that the $\mathrm{TiO}_{2}$ particles are positively charged at this $\mathrm{pH}$; therefore, the interfacial excess can be enhanced upon application of a positive potential with respect to the organic phase. On the contrary, the interfacial excess of the particles is increased at negative potentials at $\mathrm{pH} 11$ as illustrated in Figure 2b. Under these conditions, $\mathrm{TiO}_{2}$ is negatively charged due to ionization of the oxide surface.

The interfacial assembly of $\mathrm{TiO}_{2}$ upon polarization at $\mathrm{pH} 3.5$ is clearly illustrated by the differential capacitance curves in Figure 3a. These results were obtained from admittance measurements at a frequency of $6 \mathrm{~Hz}$ and an RMS amplitude of $4 \mathrm{mV}$. In this frequency range, the impedance response of the cell is determined by a single $R C$ component associated with the uncompensated resistance and the double-layer capacitance. It is observed that the differential capacitance increases at positive potentials upon addition of $\mathrm{TiO}_{2}$. To estimate the excess charge induced by the particle assembly, the capacitance curves were integrated over the whole Galvani potential difference range, under the assumption that the pzc corresponds to the minimum of the capacitance in the absence of $\mathrm{TiO}_{2}$. Although this approximation might not be entirely accurate as discussed in previous works, ${ }^{40}$ it allows for a semiquantitative analysis of the surface excess as a function of the applied potential. Figure $3 \mathrm{~b}$ shows the excess charge for various concentrations of particles in the aqueous phase. The excess charge at a given potential appears to be very slightly dependent on the concentration of the particles above $0.1 \mathrm{~g} \mathrm{dm}^{-3}$. This effect can be further illustrated after subtraction of the excess charge in the absence of the particles $\left(q_{\text {diff }}\right)$, as displayed in Figure 3c. As a first approximation, $q_{\text {diff }}$ can be taken as the effective excess charge introduced by the particle assembly. The behavior in Figure $3 \mathrm{c}$ further confirms that the onset of the particle excess concentration takes place close to $-0.10 \mathrm{~V}$ and that the excess charge reaches saturation at a given potential for particle concentrations above $0.1 \mathrm{~g} \mathrm{dm}^{-3}$

The saturation of the excess charge at high concentrations indicates that the particles cannot be considered as punctual charges as defined by the Gouy-Chapman model. Considering the $\mathrm{TiO}_{2}$ colloid as an ensemble of noninteracting charged particles distributed across the diffused layer, the magnitude of $q_{\text {diff }}$ is expected to increase monotonically with increasing bulk concentration. However, the saturation of $q_{\text {diff }}$ suggests that the organization of particles at the interface can be rationalized in terms of a potential-induced adsorption process. The particle interfacial density can be estimated from $q_{\text {diff }}$ and the average charge per particle as derived from electrophoretic measurements. Taking into account that 5-nm-radius particles exhibit an average charge of $10^{-18} \mathrm{C}$ at $\mathrm{pH} 3.5,{ }^{36}$ the charge densities estimated from an analysis of Figure 3 suggest surface particle densities on the order of $10^{12} \mathrm{~cm}^{-2}$. This high surface density approaches the limit of a close-packed arrangement of spherical particles. Nevertheless, this simplified approach should be considered cautiously, as perturbations of the local potential distribution introduced by the particle assembly as well as changes in the interfacial $\mathrm{pH}$ upon polarization are not considered. We shall come back to this discussion later in this paper.

The effect of bulk $\mathrm{pH}$ on the interfacial assembly of particles is exemplified in Figure 4. The behavior described at $\mathrm{pH} 3.5$ can be contrasted with the increase in interfacial capacitance at negative potentials at $\mathrm{pH} 11$. The differential capacitance curve in the absence of the particles remains unaffected by the $\mathrm{pH}$ of the aqueous phase. Under these conditions, negatively charged particles are assembled at the interface at negative Galvani potential differences.
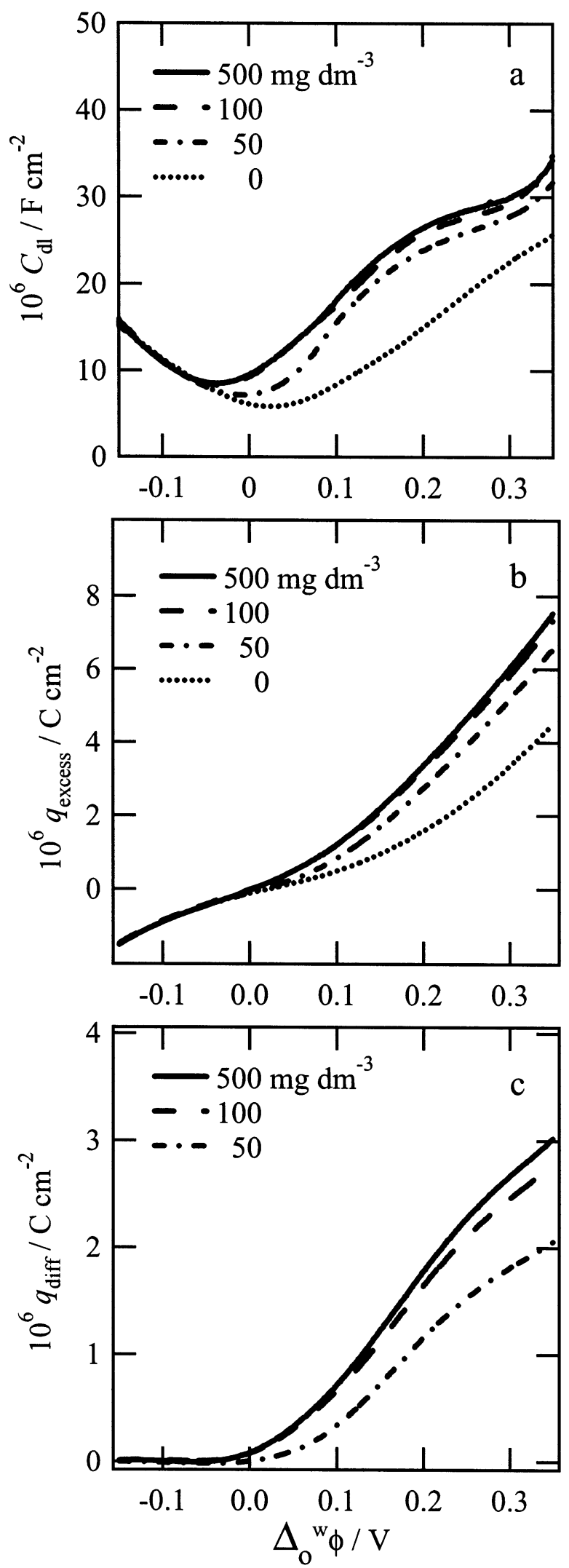

Figure 3. (a) Differential capacitance as a function of the Galvani potential difference for various $\mathrm{TiO}_{2}$ concentrations at $\mathrm{pH}$ 3.5. The differential capacitance was estimated from admittance measurements at $6 \mathrm{~Hz}$ and amplitude $4 \mathrm{mV}$ RMS. (b) Excess charge as a function of the applied potential obtained from integration of the differential capacitance. (c) Difference between the excess charge in the presence and absence of $\mathrm{TiO}_{2}$ particles.

3.2. Photoelectrochemical Behavior of $\mathrm{TiO}_{2}$ Particles at the Water|DCE Interface. Band-gap illumination of $\mathrm{TiO}_{2}$ 


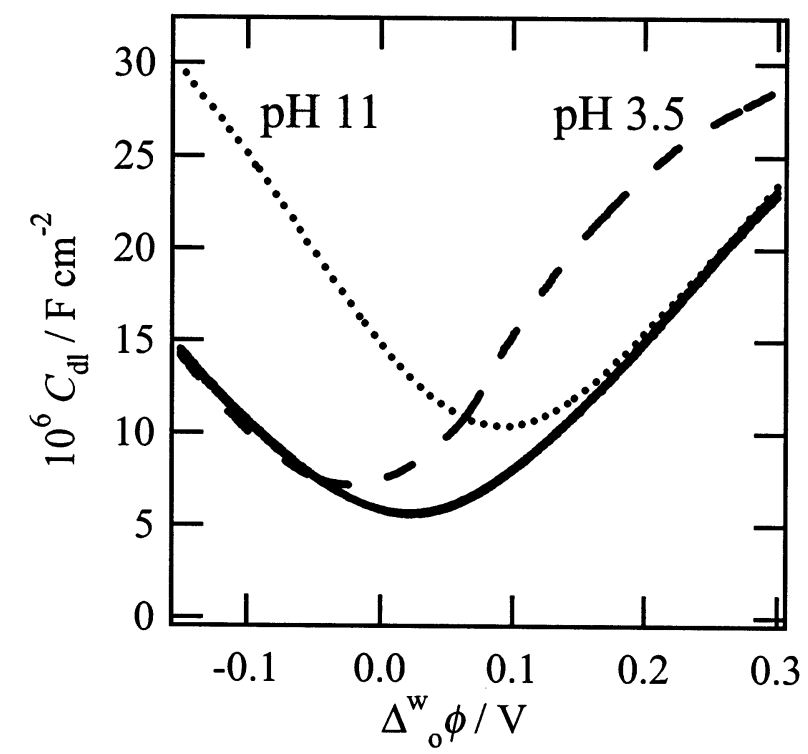

Figure 4. Capacitance potential curves in the presence of $0.1 \mathrm{~g} \mathrm{dm}^{-3}$ of $\mathrm{TiO}_{2}$ at $\mathrm{pH} 3.5$ and 11 . The solid line corresponds to the differential capacitance in the absence of the particles.

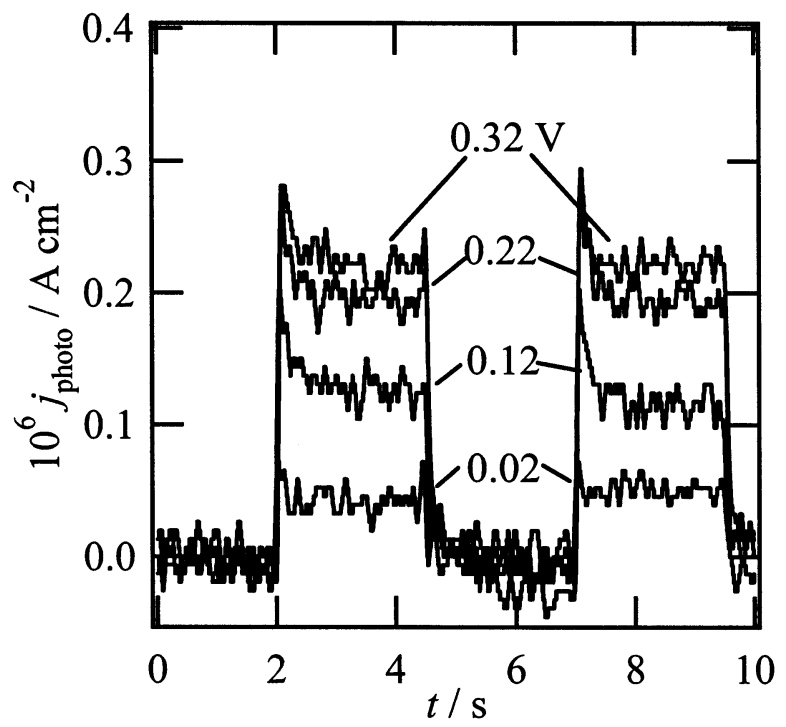

Figure 5. Photocurrent transient responses at various Galvani potential differences obtained in the presence of $0.1 \mathrm{~g} \mathrm{dm}^{-3} \mathrm{TiO}_{2}$ and $1 \mathrm{mM}$ ferrocene in DCE.

nanoparticles generates electron-hole pairs with quasi-Fermi levels approaching the energies of the conduction and valence bands ${ }^{41}$

$$
\begin{gathered}
E_{\mathrm{VB}}\left(\mathrm{TiO}_{2}\right)=3.07-(0.059 \times \mathrm{pH}) \\
E_{\mathrm{CB}}\left(\mathrm{TiO}_{2}\right)=-0.11-(0.059 \times \mathrm{pH})
\end{gathered}
$$

where $E_{\mathrm{VB}}$ and $E_{\mathrm{CB}}$ are given in volts vs SHE. Considering that the redox potential of ferrocene in DCE is $0.64 \mathrm{~V}$ vs SHE, ${ }^{42}$ heterogeneous electron injection from this donor into holes in the valence band should occur readily on thermodynamic grounds. Figure 5 shows photocurrent responses originating from the heterogeneous photooxidation of ferrocene by $\mathrm{TiO}_{2}$ across the water|DCE junction at $\mathrm{pH}$ 3.5. Similarly to the behavior observed for dye-sensitized water|DCE interfaces, no significant photoresponses are observed in the absence of particles or ferrocene. Furthermore, no photocurrents are detected upon illumination of only the bulk solutions. A sharp increase in the

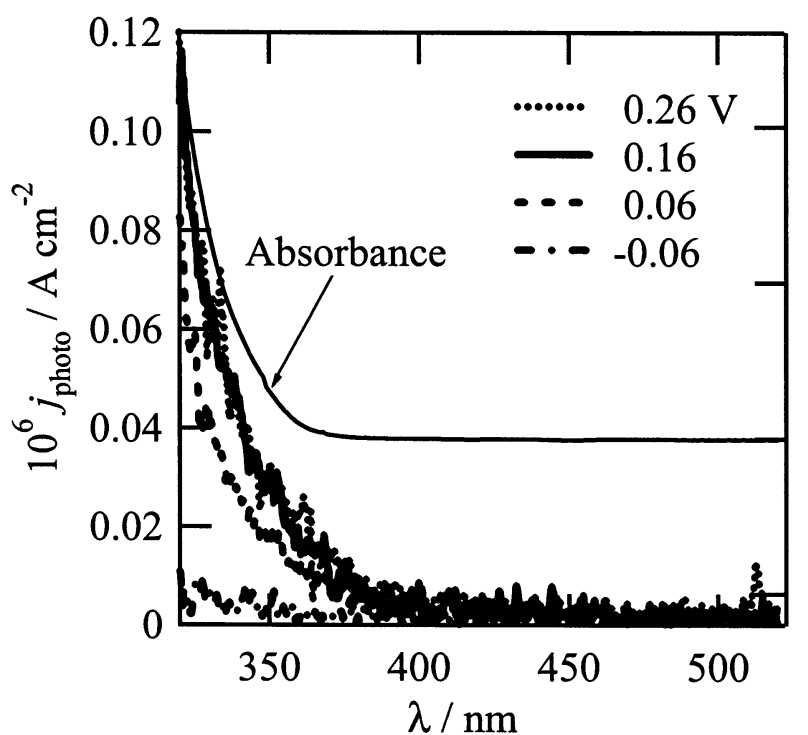

Figure 6. Photocurrent spectra at various Galvani potential differences obtained for $0.1 \mathrm{~g} \mathrm{dm}^{-3}$ of $\mathrm{TiO}_{2}$ at $\mathrm{pH} 3.5$ and $10^{-3} \mathrm{~mol} \mathrm{dm}^{-3}$ of ferrocene in DCE.

photocurrent occurs at potentials close to the pzc, which is consistent with the onset of the particle assembly at the liquid|liquid boundary region. At potentials higher than $0.1 \mathrm{~V}$, the potential dependence of the photocurrent becomes substantially weaker.

The dependence of the photocurrent on the wavelength of illumination is depicted in Figure 6. The photocurrent spectra were normalized to the incident light intensity. It is observed that the main features of the photocurrent spectra are similar to those of the UV-visible absorption spectrum superimposed in the same figure. Furthermore, a representation of $\left(j_{\text {photo }} / q I_{\mathrm{o}}\right)^{0.5}$ vs $h v$ features a linear relationship with an ordinate intercept close to $3.1 \mathrm{eV}$, coinciding with the band gap of $\mathrm{TiO}_{2}$. This behavior also indicates that the optical transition associated with the photoelectrochemical responses corresponds to an indirect transition. Some deviations were observed at lower energies, which might arise from sub-bandgap photoresponses involving surface states on the particles.

Photocurrent transients at $\mathrm{pH} 11$ in the presence of the electron acceptor tetracyanoquinodimethane (TCNQ) in DCE are displayed in Figure 7. The redox potential of TCNQ in DCE is $0.29 \mathrm{~V}$ vs SHE. ${ }^{42}$ Taking into account the energy of the conduction band given by eq 2 , the transfer of photogenerated electrons to TCNQ across the interface appears feasible. The negative photocurrents shown in Figure 7 are consistent with the transfer of a negative charge from the aqueous to the organic phase. The magnitude of the photocurrent increases as the Galvani potential is shifted to more negative values, reaching a maximum close to $0 \mathrm{~V}$. Similarly to the case of ferrocene, the photocurrent onset potential is very close to the potential of minimum capacitance illustrated in Figure 4. The rather slow relaxation observed in the presence of TCNQ is yet to be fully rationalized. From previous studies at dye-sensitized liquid|liquid interfaces, it is expected that diffusion phenomena involving TCNQ will be observed at substantially higher photocurrent densities. The dynamic features of the photocurrent transients will be addressed in subsequent publications.

The $\mathrm{pH}$ also exerts a strong effect on the transfer dynamics of photogenerated carriers across the liquid|liquid boundary. For instance, the efficiency of ferrocene photooxidation sharply decreases as the $\mathrm{pH}$ changes from 3.5 to 11 . This behavior can be rationalized in terms of an increase in the rate of oxygen 


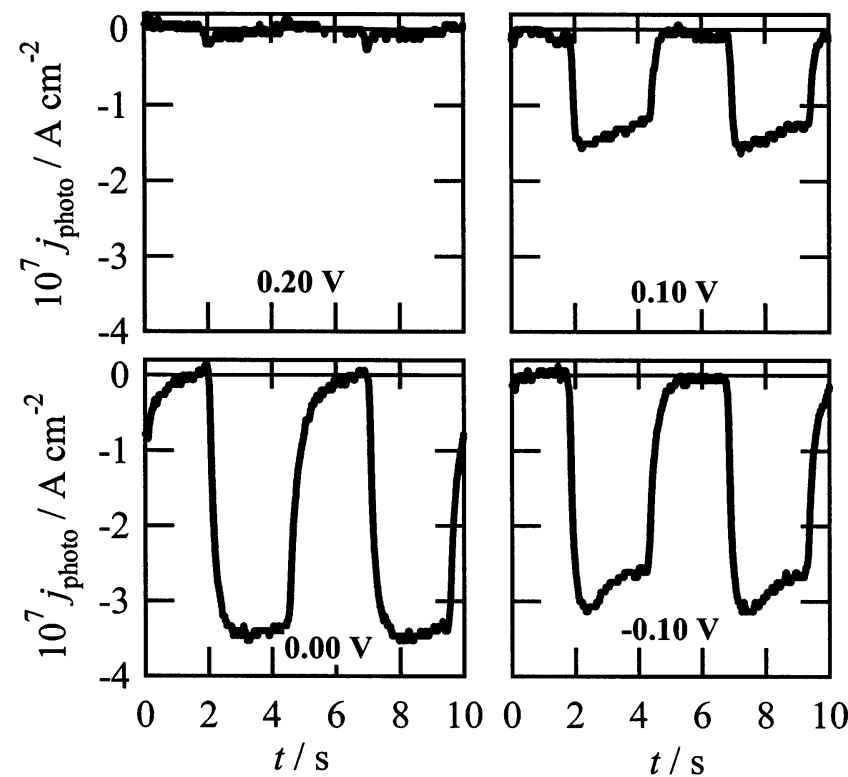

Figure 7. Photocurrent transient responses at various Galvani potential differences obtained in the presence of $0.1 \mathrm{~g} \mathrm{dm}^{-3}$ of $\mathrm{TiO}_{2}$ at $\mathrm{pH} 11$ and $10^{-3} \mathrm{~mol} \mathrm{dm}^{-3}$ of TCNQ in DCE

evolution at the particle surface at high $\mathrm{pH} .{ }^{41}$ As discussed in the next section, holes are swiftly trapped by surface $\mathrm{OH}^{-}$, leading to the formation of $\mathrm{OH}_{\mathrm{s}}{ }^{*}$. The photocurrent responses will be determined by the rates of electron capture by the surface radical from ferrocene and from the conduction band (recombination process), as well as $\mathrm{OH}_{\mathrm{s}}{ }^{\bullet}$ coupling to generate hydrogen peroxide. Conversely, the photocurrent in the presence of TCNQ decreases at low $\mathrm{pH}$, which is consistent with a decrease in the quasi-Fermi level of the photogenerated electrons. Considering that the illumination introduces a high carrier density in the particles, the quasi-Fermi level of electrons effectively merges with the edge of the conduction band; consequently, the $\mathrm{pH}$ dependence can be expressed in terms of eq 2 . Duonghong et al. have shown that a change in $\mathrm{pH}$ from 9 to 3 introduces a decrease in the rate constant for the homogeneous photoreduction of $\mathrm{MV}^{2+}$ by approximately 3 orders of magnitude. ${ }^{41} \mathrm{~A}$ similar dependence is also expected for the heterogeneous reaction across the liquid|liquid boundary, although the bimolecular rate constant can be smaller in comparison to the homogeneous process because of the distance separating the particles and the redox couple. In this case, the photocurrent responses reflect the competition between the transfer of conduction-band electrons and electron capture by oxygen at the interface. A detailed study of the $\mathrm{pH}$ dependence of the photocurrent will require stabilization of the particles in the region of 4 to 9. Steric stabilization, employing, for instance, poly(vinyl alcohol), might affect the organization of $\mathrm{TiO}_{2}$ at the interface.

As far as we are aware, these results illustrate the first photocurrent analysis of hole- and electron-transfer processes from nanoparticle assemblies to redox species in solution. These results can be somewhat related to the work by Albery et al. on $\mathrm{CdS}$ and $\mathrm{TiO}_{2}$ at optical rotating disk electrodes. ${ }^{43-45}$ However, the latter approach describes the dynamics of particle-toelectrode charge transfer and the corresponding mass-transfer phenomena. A key aspect in the studies shown here is the molecular nature of the interfacial region; consequently, the dynamics of charge transfer are free from interference arising from electronic interactions with metallic surfaces.

3.3. Dynamic Aspects of Photoinduced Hole Transfer across the Water|DCE Interface. Photocurrent potential curves
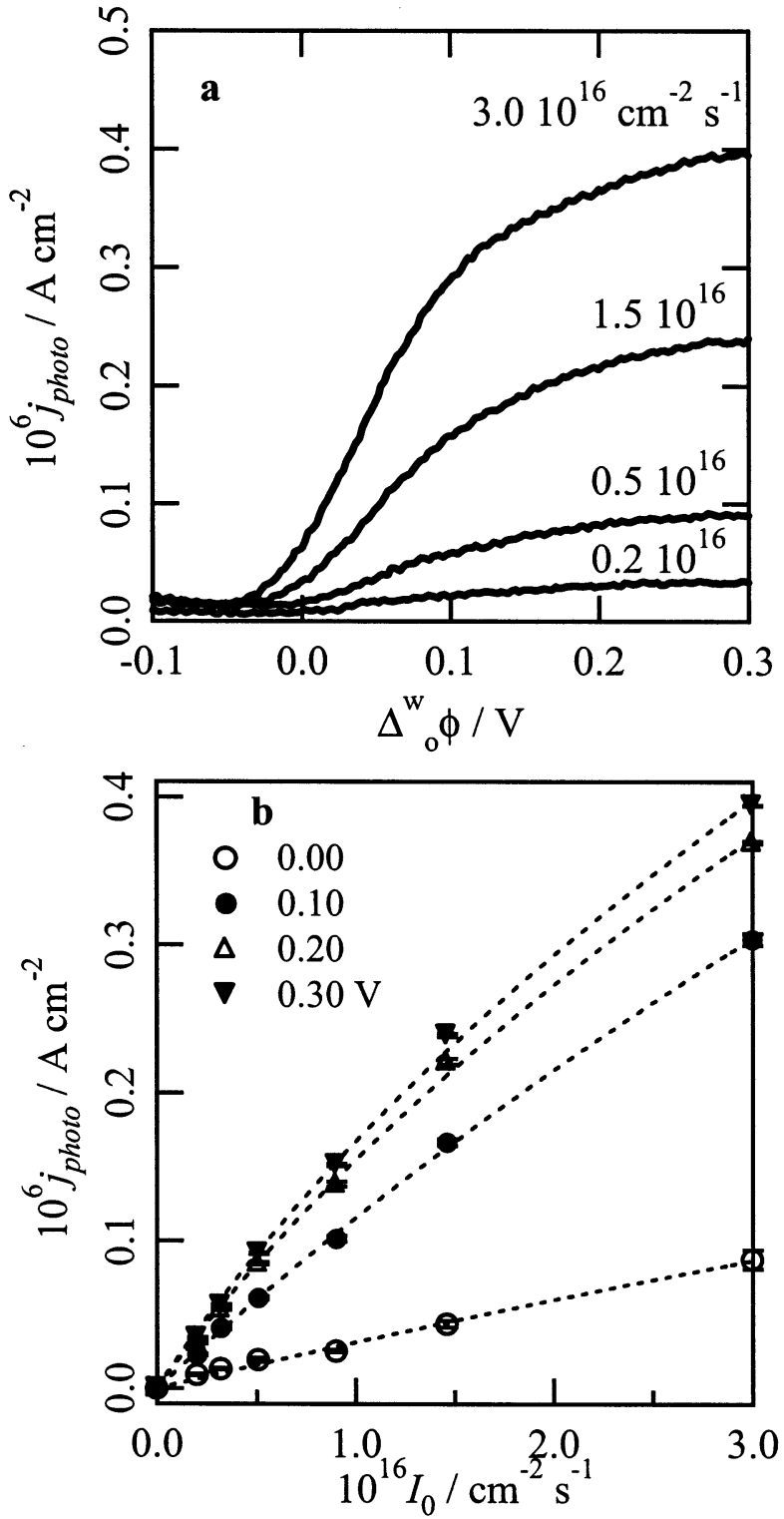

Figure 8. (a) Photocurrent potential curves obtained under $12-\mathrm{Hz}$ chopped illumination $(325 \mathrm{~nm})$ and lock-in detection at various photon fluxes. The electrolyte composition was the same as in Figure 5. (b) Photocurrent dependence on the photon flux at various constant potentials. The dashed lines correspond to nonlinear fittings of eqs 13 and 14, taking $k_{\mathrm{et}}$ and $\Gamma$ as adjustable parameters.

obtained under chopped illumination at various light intensities and lock-in detection are displayed in Figure 8a. The chopping frequency was set to $7 \mathrm{~Hz}$ to minimize phase shifts associated with the double-layer charging, typically observed at frequencies close to $100 \mathrm{~Hz}$. The photocurrent onset potential at ca. -0.05 $\mathrm{V}$ coincides with the increase in $q_{\text {diff }}$ illustrated in Figure 3 under identical conditions. This behavior unequivocally relates the photoelectrochemical responses with the formation of the nanoparticle assembly at the interface. However, the potential dependences of $j_{\text {photo }}$ and $q_{\text {diff }}$ show clear differences at potentials above $0.1 \mathrm{~V}$. The weak dependence of the photocurrent on the Galvani potential difference in this potential range contrasts with the monotonically increment of $q_{\text {diff }}$ as illustrated in Figure 3. This apparent dichotomy between $j_{\text {photo }}$ and $q_{\text {diff }}$ might indicate that the former reflects changes not only in the particle surface density but also in the average charge per particle. The latter can be affected by local $\mathrm{pH}$ changes associated with the polarization of the liquid|liquid boundary. Nonlinear optical 
studies at polarizable liquid|liquid interfaces have shown that the interfacial $\mathrm{pH}$ decreases as the Galvani potential difference increases. ${ }^{46}$ This phenomenon arises from the concentration polarization of protons exerted by the local potential. ${ }^{47}$

The hole-transfer reaction is likely to take place via the radical $\mathrm{OH}_{\mathrm{s}}{ }^{\bullet}$ generated at the particle surface. Indeed, the surface $\mathrm{OH}$ groups act as a deep trap level for valence-band holes, which can further react to generate surface-bound hydrogen peroxide. ${ }^{48-55}$ The overall mechanism can be represented by

$$
\begin{gathered}
\mathrm{X}_{\mathrm{s}}+h v \rightarrow \mathrm{h}_{\mathrm{VB}}{ }^{+}+\mathrm{e}_{\mathrm{CB}}^{-} \\
\mathrm{h}_{\mathrm{VB}}{ }^{+}+\mathrm{OH}_{\mathrm{s}}{ }^{-} \stackrel{k_{1}}{\longrightarrow} \mathrm{OH}_{\mathrm{s}} \\
\mathrm{e}_{\mathrm{CB}}^{-}+\mathrm{OH}_{\mathrm{s}} \stackrel{k_{2}}{\longrightarrow} \mathrm{OH}_{\mathrm{s}}^{-} \\
\mathrm{Fc}_{\mathrm{DCE}}+\mathrm{OH}_{\mathrm{s}} \stackrel{k_{\mathrm{et}}^{\mathrm{II}}}{\longrightarrow} \mathrm{Fc}_{\mathrm{DCE}}^{+}+\mathrm{OH}_{\mathrm{s}}^{-} \\
\mathrm{e}_{\mathrm{CB}}^{-}+\mathrm{Y} \stackrel{k_{3}^{\mathrm{II}}}{\longrightarrow} \mathrm{Y}^{-}
\end{gathered}
$$

where $X_{\mathrm{s}}$ represents a site in the nanocrystalline lattice that is photoionized under band-gap illumination and $\mathrm{Y}$ is an electron acceptor. Electrons in the conduction band can be captured by oxygen in solution. Taking $k_{\text {et }}$ and $k_{3}$ as pseudo-first-order rate constants with respect to the concentration of the radical intermediate and the electron density in the conduction band, respectively, i.e.

$$
\begin{gathered}
k_{\mathrm{et}}=k_{\mathrm{et}}^{\mathrm{II}}[\mathrm{Fc}] \\
k_{3}=k_{3}^{\mathrm{II}}[\mathrm{Y}]
\end{gathered}
$$

the differential equations for the density of holes in the valence band $\left(\left[\mathrm{h}^{+}\right]\right)$, of surface radicals $\left(\left[\mathrm{OH}_{\mathrm{s}}{ }^{\circ}\right]\right)$, and of electrons in the conduction band $\left(\left[\mathrm{e}^{-}\right]\right)$can be written as

$$
\begin{gathered}
\frac{\mathrm{d}\left[\mathrm{h}^{+}\right]}{\mathrm{d} t}=I_{0} \sigma \Gamma-k_{1}\left[\mathrm{OH}_{\mathrm{s}}^{-}\right]\left[\mathrm{h}^{+}\right] \\
\frac{\mathrm{d}\left[\mathrm{OH}_{\mathrm{s}}{ }^{+}\right]}{\mathrm{d} t}=k_{1}\left[\mathrm{OH}_{\mathrm{s}}^{-}\right]\left[\mathrm{h}^{+}\right]-k_{2}\left[\mathrm{OH}_{\mathrm{s}}{ }^{\circ}\right]\left[\mathrm{e}^{-}\right]-k_{\mathrm{et}}\left[\mathrm{OH}_{\mathrm{s}}{ }^{\cdot}\right] \\
\frac{\mathrm{d}\left[\mathrm{e}^{-}\right]}{\mathrm{d} t}=I_{0} \sigma \Gamma-k_{2}\left[\mathrm{OH}_{\mathrm{s}}{ }^{-}\right]\left[\mathrm{e}^{-}\right]-k_{3}\left[\mathrm{OH}_{\mathrm{s}}{ }^{\bullet}\right]
\end{gathered}
$$

where $I_{0}, \sigma$, and $\Gamma$ correspond to the incident photon flux, light capture cross section, and particle surface density, respectively. It follows from eqs $10-12$ that the steady-state concentration of the surface radical $\left(\left[\mathrm{OH}_{\mathrm{s}}{ }^{\circ}\right]_{\mathrm{ss}}\right)$ can be implicitly expressed as

$$
k_{\mathrm{et}}\left[\mathrm{OH}_{\mathrm{s}}^{\bullet}\right]_{\mathrm{ss}}\left(k_{2}\left[\mathrm{OH}_{\mathrm{s}}^{\bullet}\right]_{\mathrm{ss}}+k_{3}\right)-k_{3} I_{0} \sigma \Gamma=0
$$

and the photocurrent density is simply given by the rate of charge transfer from ferrocene

$$
j_{\text {photo }}=q k_{\mathrm{et}}^{\mathrm{II}}[\mathrm{Fc}]\left[\mathrm{OH}_{\mathrm{s}}^{\bullet}\right]=q k_{\mathrm{et}}\left[\mathrm{OH}_{\mathrm{s}}^{\bullet}\right]
$$

From eqs 13 and 14, it can be deduced that, for the limiting case where the conduction-band electrons are readily captured prior to recombination $\left(k_{2}\left[\mathrm{OH}_{\mathrm{s}}\right]_{\mathrm{ss}} \ll k_{3}\right)$, the photocurrent is simply given by the generation factor $I_{0} \sigma \Gamma$. This case corresponds to a quantum yield of unity for the hole-transfer process. On the other hand, if the lifetime of electrons in the particle is rather long $\left(k_{2}\left[\mathrm{OH}_{\mathrm{s}}{ }^{\circ}\right]_{\mathrm{ss}} \gg k_{3}\right)$ eq 14 can be rewritten as

$$
\frac{j_{\text {photo }}}{q}=\sqrt{\frac{k_{3}}{k_{2}} k_{\mathrm{et}} I_{0} \sigma \Gamma}
$$

As expected, in the presence of electron-hole recombination, the photocurrent intensity is proportional to the square root of the light intensity.

The dependence of the photocurrent on the photon flux is illustrated in Figure $8 \mathrm{~b}$ for various Galvani potential differences. It is observed that the photocurrent density exhibits a nonlinear dependence over the range studied. To further analyze this behavior, independent estimations of the parameters $k_{2}$ and $k_{3}$ should be considered. For instance, dynamic studies in bulk solutions have shown that the rate constant for electron capture by oxygen is on the order of $10^{-7} \mathrm{~cm} \mathrm{~s}^{-1} .^{2}$ On the other hand, values of $k_{2}$ of $10^{-14} \mathrm{~cm}^{3} \mathrm{~s}^{-1}$ have been obtained from dynamic photocurrent measurements on single-crystal electrodes close to the flat-band potential. ${ }^{54}$ The photon-capture cross section at $325 \mathrm{~nm}$ can be taken as $\sigma=8 \times 10^{-15} \mathrm{~cm}^{2} .{ }^{36}$ The dashed lines in Figure $8 \mathrm{~b}$ illustrate the fittings employing eqs 13 and 14, taking $k_{\text {et }}$ and $\Gamma$ as the adjustable parameters. These two parameters mostly affect the overall photocurrent density, whereas the ratio $k_{2} / k_{3}$ determines the deviation from linearity of the photocurrent as a function of light intensity. As illustrated in Figure $8 \mathrm{~b}$, the initial values taken for $k_{2}$ and $k_{3}$ provide acceptable fittings to the experimental results.

The previous fitting shows that the density of particles increases from 0.5 to $3.5 \times 10^{10} \mathrm{~cm}^{-2}$ as the applied potential is increased from 0 to $0.3 \mathrm{~V}$. These values are effectively 2 orders of magnitude smaller than the surface density estimated from the admittance measurements. These results suggest that the effective charge per particle at the surface is significantly larger than that in the bulk. Indeed, it is expected that the surface density is determined not only by the size of the particles but also by the electrostatic repulsions that counteract aggregation forces. The potential dependence of the surface density might reflect the equilibrium between the effect of the electrostatic field on the particle distribution and lateral electrostatic forces.

The present analysis also reveals that the phenomenological pseudo-first-order rate constant $k_{\text {et }}$ is on the order of $10^{4} \mathrm{~s}^{-1}$. Interestingly, the phenomenological $k_{\mathrm{et}}$ is comparable to the rate constants obtained for the heterogeneous photooxidation of ferrocene derivatives by porphyrin species under similar conditions. ${ }^{34}$ By contrast, this rate constant exhibits a rather weak potential dependence, suggesting that the driving force for hole transfer remains unaffected by the Galvani potential difference. A relevant point to consider is that the size of the particles is larger than the average thickness of the solvent distribution profiles at the liquid|liquid boundary, i.e., $1 \mathrm{~nm}$. Therefore, a new formulation for heterogeneous electron transfer should be developed beyond the simplified model of two reactants separated by a sharp boundary between two dielectric media. ${ }^{56-59}$

\section{Conclusions}

The photoreactivity of $\mathrm{TiO}_{2}$ nanoparticles in solution can be studied by photocurrent measurements at liquid|liquid interfaces under potentiostatic conditions. The particles can be electrostatically assembled at the interface depending on the $\mathrm{pH}$ of the aqueous phase. For pH's lower than 4.7, the $\mathrm{TiO}_{2}$ particles are positively charged as a result of the protonation of the surface oxide. Positive polarization of the interface leads to an increase of the surface excess charge. At potentials more positive than the pzc, the excess charge becomes independent of the particle concentration for values above $0.1 \mathrm{~g} \mathrm{dm}^{-3}$. This behavior 
suggests that the organization of the particles in the interfacial region is strongly determined by lateral electrostatic interactions rather than concentration polarization. Furthermore, it appears that the average charge per particle is strongly affected by the local $\mathrm{pH}$, which is a function of the Galvani potential difference.

Band-gap illumination of the particles at the interface can lead to the heterogeneous transfer of holes and electrons to redox species located in the organic phase. Photogenerated holes are readily trapped by hydroxyl groups at the surface, generating adsorbed $\mathrm{OH}_{\mathrm{s}}$. Preliminary estimations based on typical lifetimes for conduction band electrons and $\mathrm{OH}_{\mathrm{s}}{ }^{\bullet}$ indicate that heterogeneous electron transfer from ferrocene take place on the microsecond time scale. For high $\mathrm{pH}$, the efficiency of the heterogeneous photooxidation process is affected by a decrease in the lifetime of $\mathrm{OH}_{\mathrm{s}}{ }^{\circ}$ probably due to an increase in the rate of oxygen evolution at the particle surface. In addition, increasing $\mathrm{pH}$ induces a shift in the particle Fermi level, increasing the driving force for the heterogeneous transfer of conduction-band electrons. Under these conditions, the photoreduction of TCNQ is observed at negative potentials.

Finally, the present studies open new possibilities for contactless photoelectrochemical and spectroscopic studies of nanoparticles in the presence of a static electric field. Indeed, this report describes the first direct measurement of the rate of charge transfer from nanoparticles to redox species in solution. By contrast, time-resolved spectroscopy, EPR, pulse radiolysis, and other techniques only monitor the generation of products as result of the photochemical reactions. We strongly believe that the implications of these observations are far-reaching. For instance, by effectively controlling the surface density of particles, we expect to address fundamental information on the reactivity of single particles vs assemblies with well-defined redox properties at the molecular level.

Acknowledgment. This research is partly financed by the EPFL, the Fonds National de la Recherche Scientifique (Project 20-55692.98), and Office Fédérale de l'Education et de la Science (COST action D15, Project C02.0010). The technical assistance by Valérie Devaud is also gratefully acknowledged.

\section{References and Notes}

(1) Fujishima, A.; Hashimoto, K.; Watanabe, T. TiO2 Photocatalysis Fundamentals and Applications; BKC: Tokyo, 1999.

(2) Grätzel, M. Heterogeneous Photochemical Electron Transfer; CRC Press: Boca Raton, FL, 1988.

(3) Hagfeldt, A.; Bjorksten, U.; Lindquist, S. E. Sol. Energy Mater. Sol. Cells 1992, 27, 293-304.

(4) Hagfeldt, A.; Lindstrom, H.; Sodergren, S.; Lindquist, S. E. J. Electroanal. Chem. 1995, 381, 39-46.

(5) Rensmo, H.; Lindstrom, H.; Sodergren, S.; Willstedt, A. K. Solbrand, A.; Hagfeldt, A.; Lindquist, S. E. J. Electrochem. Soc. 1996, 143 3173-3178.

(6) Rothenberger, G.; Fitzmaurice, D.; Gratzel, M. J. Phys. Chem. 1992 96, 5983-5986.

(7) Solbrand, A.; Lindstrom, H.; Rensmo, H.; Hagfeldt, A.; Lindquist, S. E.; Sodergren, S. J. Phys. Chem. B 1997, 101, 2514-2518.

(8) Vanmaekelbergh, D.; de Jongh, P. E. J. Phys. Chem. B 1999, 103 747-750.

(9) Redmond, G.; Fitzmaurice, D. J. Phys. Chem. 1993, 97, 1426430.

(10) Boschloo, G.; Fitzmaurice, D. J. Phys. Chem. B 1999, 103, $2228-$ 2231.

(11) Boschloo, G.; Fitzmaurice, D. J. Electrochem. Soc. 2000, 147, $1117-1123$

(12) Duffy, N. W.; Peter, L. M.; Wijayantha, K. G. U. Electrochem. Commun. 2000, 2, 262-266.

(13) Peter, L. M.; Ponomarev, E. A.; Franco, G.; Shaw, N. J. Electrochim. Acta 1999, 45, 549-560.

(14) Peter, L. M.; Wijayantha, K. G. U. Electrochem. Commun. 1999, $1,576-580$.

(15) Peter, L. M.; Wijayantha, K. G. U. Electrochim. Acta 2000, 45 , $4543-4551$
(16) Haque, S. A.; Tachibana, Y.; Willis, R. L.; Moser, J. E.; Gratzel, M.; Klug, D. R.; Durrant, J. R. J. Phys. Chem. B 2000, 104, 538-547.

(17) Durrant, J. R.; Tachibana, Y.; Mercer, I.; Moser, J. E.; Gratzel, M.; Klug, D. R. Z. Phys. Chem.-Int. J. Res. Phys. Chem. Chem. Phys. 1999, $212,93-98$.

(18) Moser, J. E.; Gratzel, M. Chimia 1998, 52, 160-162.

(19) Moser, J. E.; Wolf, M.; Lenzmann, F.; Gratzel, M. Z. Phys. Chem. Int. J. Res. Phys. Chem. Chem. Phys. 1999, 212, 85-92.

(20) Tachibana, Y.; Moser, J. E.; Gratzel, M.; Klug, D. R.; Durrant, J. R. J. Phys. Chem. 1996, 100, 20056-20062.

(21) Duffy, N. W.; Peter, L. M.; Rajapakse, R. M. G.; Wijayantha, K. G. U. Electrochem. Commun. 2000, 2, 658-662.

(22) Bakkers, E.; Marsman, A. W.; Jenneskens, L. W.; Vanmaekelbergh, D. Angew. Chem., Int. Ed. 2000, 39, 2297-2299.

(23) Bakkers, E.; Roest, A. L.; Marsman, A. W.; Jenneskens, L. W.; de Jong-van Steensel, L. I.; Kelly, J. J.; Vanmaekelbergh, D. J. Phys. Chem. B 2000, 104, 7266-7272.

(24) Hickey, S. G.; Riley, D. J. J. Phys. Chem. B 1999, 103, 45994602 .

(25) Hickey, S. G.; Riley, D. J.; Tull, E. J. J. Phys. Chem. B 2000, 104 $7623-7626$

(26) Bakkers, E.; Reitsma, E.; Kelly, J. J.; Vanmaekelbergh, D. J. Phys. Chem. B 1999, 103, 2781-2788.

(27) Bakkers, E.; Kelly, J. J.; Vanmaekelbergh, D. J. Electroanal. Chem 2000, 482, 48-55.

(28) Fermín, D. J.; Ding, Z. F.; Duong, H. D.; Brevet, P. F.; Girault, H. H. Chem. Commun. 1998, 1125-1126.

(29) Fermín, D. J.; Ding, Z. F.; Duong, H. D.; Brevet, P. F.; Girault, H. H. J. Phys. Chem. B 1998, 102, 10334-10341.

(30) Fermín, D. J.; Duong, H. D.; Ding, Z. F.; Brevet, P. F.; Girault, H. H. Phys. Chem. Chem. Phys. 1999, 1, 1461-1467.

(31) Fermín, D. J.; Duong, H. D.; Ding, Z. F.; Brevet, P. F.; Girault, H. H. J. Am. Chem. Soc. 1999, 121, 10203-10210.

(32) Jensen, H.; Kakkassery, J. J.; Nagatani, H.; Fermín, D. J.; Girault, H. H. J. Am. Chem. Soc. 2000, 122, 10943-10948

(33) Jensen, H.; Fermín, D. J.; Girault, H. H. Phys. Chem. Chem. Phys 2001, 3, 2503-2508.

(34) Eugster, N.; Fermín, D. J.; Girault, H. H. J. Phys. Chem. B 2002. $106,3428-3433$

(35) Moser, J. E.; Grätzel, M. Helv. Chim. Acta 1982, 65, 1436-1444.

(36) Moser, J. E.; Grätzel, M. J. Am. Chem. Soc. 1983, 105, 65476555.

(37) Moser, J.; Grätzel, M. J. Am. Chem. Soc. 1984, 106, 6557-6564.

(38) Ding, Z. Ph.D. Thesis, Ecole Polytechnique Fédérale de Lausanne, Lausanne, Switzerland, 1999

(39) Nagatani, H.; Iglesias, R. A.; Fermín, D. J.; Brevet, P. F.; Girault, H. H. J. Phys. Chem. B 2000, 104, 6869-6876.

(40) Volkov, A. G. Langmuir 1996, 12, 3315-3319.

(41) Duonghong, D.; Ramsden, J.; Grätzel, M. J. Am. Chem. Soc. 1982, 104, 2977-2985

(42) Fermín, D. J.; Lahtinen, R. In Liquid Interfaces in Chemical, Biological, and Pharmacentical Applications; Volkov, A., Ed.; Marcel Dekker: New York, 2001; pp 179-228.

(43) Boxall, C.; Albery, W. J. Phys. Chem. Chem. Phys. 2000, 2, 36313639.

(44) Boxall, C.; Albery, W. J. Phys. Chem. Chem. Phys. 2000, 2, 36413650 .

(45) Boxall, C.; Albery, W. J. Phys. Chem. Chem. Phys. 2000, 2, 36513662

(46) Naujok, R. R.; Higgins, D. A.; Hanken, D. G.; Corn, R. M. J. Chem. Soc.-Faraday Trans. 1995, 91, 1411-1420.

(47) Zhao, X.; Ong, S.; Wang, H.; Eisenthal, K. B. Chem. Phys. Lett. 1993, 214, 203-207.

(48) Salvador, P.; Decker, F. J. Phys. Chem. 1984, 88, 6116-6120.

(49) Salvador, P. J. Phys. Chem. 1985, 89, 3863-3869.

(50) Ferrer, I. J.; Muraki, H.; Salvador, P. J. Phys. Chem. 1986, 90 , $2805-2807$

(51) Tafalla, D.; Salvador, P. Ber. Bunsen-Ges. Phys. Chem. Chem. Phys 1987, 91, 475-479.

(52) Tafalla, D.; Salvador, P.; Benito, R. M. J. Electrochem. Soc. 1990 , 137, 1810-1815.

(53) Gonzalez, M. L. G.; Salvador, P. J. Electroanal. Chem. 1992, 325, $369-376$.

(54) Fermín, D. J.; Ponomarev, E. A.; Peter, L. M. In Photoelectrochemistry; Rajeshwar, K., Peter, L. M., Fujishima, A., Meissner, D., Tomkiewich, M., Eds.; The Electrochemical Society: Paris, 1997; p 62

(55) Semenikhin, O. A.; Kazarinov, V. E.; Jiang, L.; Hashimoto, K.; Fujishima, A. Langmuir 1999, 15, 3731-3737.

(56) Marcus, R. A. J. Phys. Chem. 1990, 94, 4152-4155.

(57) Marcus, R. A. J. Phys. Chem. 1990, 94, 7742.

(58) Marcus, R. A. J. Phys. Chem. 1990, 94, 1050-1055.

(59) Marcus, R. A. J. Phys. Chem. 1991, 95, 2010-2013. 